\title{
EL MUNDO DEL CORTESANO
}

En su versión del Cortesano, Boscán traslada a España un cuadro idealizado de la sociedad italiana del Renacimiento. I,a modalidad léxico de esta transmisión, en lo que tiene de idéntico o muy parecido al original, se sustrae al propósito comparativo de nuestro estudio. Séanos permitido, sin embargo, asentar brevemente algunas nociones de conjunto para encuadrar una que otra diferencia que hemos observado durante la lectura del texto español.

I a jerarquía social reflejada en el libro de Castiglione tiene su ápice en el príncipe, o señor de una corte ideal, que en la mente del autor es la de Urbino, y cuyo ejemplo debería extenderse a muchas otras ciudades de Italia. Al príncipe le rodea un séquito de nobles, llamados por otro nombre cortegiani. I. a cortesanía y el buen linaje pueden separarse sólo en teoría. Por la alcurnia de su nacimiento, el hombre de corte se distingue, por una parte, del cilladino, y por otra, del labrador.

En el Libro del Corlegiano los que viven al margen del mundo aristocrático de las cortes están como sobreentendidos: son los espectadores anónimos cuya presencia da relieve a los lances y destrezas del hombre de corte, o están sumidos en el nombre colectivo del vulgo, sinónimo de ignorancia y volubilidad, y término de comparación que sirve para ensalzar la superioridad del sabio. Ahora bien, la actitud de los escritores españoles renacentistas hacia el vulgo es demasiado conocida para que nos detengamos en ella ${ }^{1}$.Boscán no constituye ninguna excepción en el empleo de la palabra vulgo ("el loco y profano vulgoi), p. 382 de la edi-

1 Cf. A. Brit., Ll renacimienlo español (Zaragoza I944), p. I 16; A. Castro, El pensamiento de Cervanles (Madrid 1925), pp. $210-211$; las notas de W. L. I'TCHTEl? en su edición de Lope de Vega, El sembrar en buena tierra (Nueva York, Londres r944), pp. 198-199, y el ensayo de O. H. Gries, "On the Attitude toward the $V$ ulgo in the Spanish Siglo de Orow, Studies in the Renaissance IV (1957), pp. 190-200. 
ción de I942), y, con respecto a los campesinos, vemos que extrema la nota clespectiva:

contadinio (I 35, 4I de la ed. de 1947) - klombres baxos y aldeanost (74).

Más significativo, para el parangón de la mentalidad social de los dos países, es el eclipse, en la versión, de otra clase de la sociedad. En el cuarto libro, y más especialmente en el pequeño tratado de regimine principum, que allí inserta Castiglione para constituir al cortesano en preceptor de gobernantes, nuestro autor ha de darle su debido lugar al ciudadano, sujeto de las leyes del Estado, y espejo de la ejemplaridad del principe. Alıora bien, cindadano sólo aparece una vez en el texto español (IV II, 3I-326). Para Boscán los ciltadini son "los moradores" (IV 2I, 24-337, cf. en las Corles alos moradores destos reinos»), o simplemente, .el pueblo (IV 23, II - 339; 33, 22 - 350).

Asf la presencia del ciltadino, ya tan disminulda en el libro de Castiglione, se encubre casi por completo en la versión; lo cual, visto en la perspectiva de la historia de España, me parece sintomático. La palabra ciudadano aparece desde los primeros documentos como traducción de civis en su acepción fundamental de habitante de la ciudad ("Cipdadanos son todos aquellos que moran en las cipdades o en las villas que son como cipdadesn) ${ }^{2}$. En este sentido identificador y discriminador, la palabra se lialla esporádicamente también en los Fucros, en las Corles, en las Recopilaciones, y descle luego también en las letras españolas desde Berceo (Mil. 653), en todas las Crónicas, y en las obras doctrinales afines al Corlisano ${ }^{2}$, pero muy raramente es portadora de un ideal político y hu-

1 Vidal Mayor, Ms. Perrins II2, fol. 236 bacf., p. ej., ERNES'O MAYER, Historia de las instituciones sociales y politicas en España y Portugal durante los siglo $\mathrm{V}$ a XIV, vol. I (Madrid I925), especialmente los capitulos "La ciudad y el campo* (vol. I, pp. 43 ss.), y iLa población urbanan (pp. 238-251). Si en lugar de limitarnos a unos escarceos literarios ahondáramos el estudio de la estructura social española, nos enfrentariamos con una estratificación mucho més difícil de deslindar, y complicada, además, por la inultitud de términos'(burgut's, hombre bueno, hombre honrado, ruano), que sirven para distinguir a la capa unís alta de la población urbana, de los mercaderes y oficiales. Pero aquil no se trata de rehacer la listoria social de España sino de plantear el problema de su participación en el ideal civil propugnado por el Quatlrocento.

2 Por ejemplo, Guevara, ell su Desperlador de corlesanos (ed. de Paris, s. a.). distingue entre el ciudadano y el caballero (p. 107), y el ciudadano y el cortesano (p. 75), aun sin quitarle a aquél la posibiliclad de subir por la escala social hasta privar en la corte ( p. 63). Pero también notamos que la palabra cindadano ocurre con más frecuencin ell obras adaptadas del italiano, como el ya citado Galateo español de Gración Dantisco, pp. 10, 26, 27, 71, 77, 108. 
mano. Ese humanismo civil, por el cual se destaca con hondas vicisitudes el Quattrocento italiano, y que tan perspicazmente han historiado Eugenio Garin', Hans Baron 2 y otros investigadores, ¿tiene algún eco en España? ¿O no ha de decirse más bien que el ideal del ciudadano, o sea del hombre que por su iniciativa, actividad y disciplina forja la vida de la comunidad civil, queda obscurecido tanto por la primacía de las armas, encarnadas en el caballero, como por la superioridad, inculcada en términos estoicos y cristianos, del hombre contemplativo? Aun si nos quedamos en la superficie de obras similares (de retratos literarios, por ej.), la palabra cittadino puede servirnos de criterio para establecer concretamente una diferençia esencial. En las Vite di uomini illustri de Vespasiano da Bisticci (ed. Bologna, I892), todos los honores están conmensurados a "le dignití che si possoro dare a uno cittadino" ${ }^{3}$. No es así en las Generaciones y scmblanzas de Pérez de Guzmán, en cuya galería de personajes 110 caben sino reyes, almirantes, maestros, nobles, caballeros y prelados.

Iista digresión parecerá más justificada si se considera la ausencia de otro miembro de la misma raíz latina. Es sabido que civil -y hasta civilidad- en castellano adquirió el sentido de "vil» y de "cruel»."

1 Cf. Der italienische Humanismus (Berna 1947). publicado también en Italia, L'umanesimo italiano (Bari 1952). Véase particularmente el segundo capitulo (pp. 5 I ss.).

$2 \mathrm{Cf}$, entre otros escritos del autor, los dos fundamentales tomos titulados The Crisis of the Early Italian Renaissance (Princeton 1955).

- II 2I7, 258; III 257 y passin.

- Ya Juan di Valdés, en el Diálogo de la lengua, comentando el dicho "Caséwe con la cevil por el florin», hacla notar la diferencia entre el sentido latino de civil y el uso vulgar (ed. cit., p. I84). Véanse los textos del siglo XV y XVI que reproduce M. R. LIDA en su nota "Civil 'cruel'», NRFH, I (1947), 80-85; y los del siglo xvir que incluye M. Rosmera-Navarro en su comentario del Criticón de Gracián (Filadelfia I938), vol. I, p. I 29. Los poetas cultos emplean civil en su sentido latino, por reminiscencia, sobre todo, de la Farsalia de Lucano ("la más que civil batalla»). La distinción entre derecho civil y derecho criminal y entre materias civiles y curiales contribuiria a conservar la acepción primitiva. Asimismo, la tradición aristotélica trae consigo en lo politico el enfoque doctrinal de la comunidad civil (cf., por ej., el Regimiento de principes de Egidio Romano romanceado por GARCfA DE CASTROJLRIZ: "E por ende el omne es naturalmente civil... bevir civilmente es cosa natural al omme [fol. I 57 r y $\mathrm{v}$ de la ed. de Sevilla de r 494]; o un tratado en lengua vernácula como la Suma de politica de Rodrigo Sínciniz de Arevalo, ell la edición de JuAN Brisiyto (Madrid 1944, p. Iog y passim). Asimismo, en lo ético, Aristóteles lleva a considerar la vida civil entre los distintos géneros de existencia ("tres vidas menciona el filósofo en el tercer libro de las Éticas», es- 
Boscán, por su parte, evita el uso de la palabral, y tracluce:

le cose civili ( 47,36$)$,

el gobierno de la república (92);

non aveano... la sapienza civile di congregarsi

insieme nello città (IV II, 24).

no alcanzaban aquel otro saber que era necesario

para que supiesen estar juntos en las ciudades y

hacer sus repúblicas (326);

la virtù civile (IV II, 29),

la virtud que compone y concierta el trato lumano (326);

civile (IV 22,4) propia para una buena ciudad (338);

in guerra civile (IV 17, 24),

cuando el pueblo echa a dos partes y pelean entre sí unos y otros (332);

Así de la traducción desaparece una de las palabras claves del legado espiritual de Roma, cuya ausencia no sólo es muy significativa para la época, sino que tiene, en ni sentir, una repercusión histórica de siglos en

cribe Diego de Valera, "voluptuosa, civil o polltica, y contemplativan, Defenssa de virtuosas nutugeres, MS. 12.672 de la Biblioteca Nacional, fol. II 7 v.). Seria interesante ver hasta qué punto las obras literarias recogen lo civil como concepto de vida. Recuerdo, por de pronto, que ENRIQUE DE VILLENA, en sus Doze trabajos de Hércules, dedica una sección especial al restado de çibdadano (véase mi edición, Madrid 1958), pp. 54-55 y que habla de la acevil çiençian (p. 54, I4) como también de "regirse çevilınente las çilbdades» (p. 54, 16). También labría que recoger las alabanzas de las riquezas y de la vida activa que aparecen en la prosa y aun en los Cancioneros del siglo xv, y rastrear la posible fortuna en España de tratados como cl Della vila civile de Mateo Palmieri (cuya versión, sin embargo, no me consta).

1 En las poeslas de nuestro autor, civil aparece en la acepción corriente de "cruel", "fietos, tcon un civil y mentiroso trato (Obras, ed. cit., fol. 147 r); "De nonada os vendrá un civil despechor ( $158 \mathrm{r}$ ), y siempre en la Octava rima con juego de palabra: atorres habréis en vuestro pensamiento, civiles sobre ser torres de vientor (ib.). Aunque esta acepción de civil se ha perdido en la lengua actual, quizá vuelva a adquirir por otros caminos matices deteriores. Ixclulda del vocabulario nacional, por silencioso acuerdo de las dos partes, la mención de iguerra civil, se emplea civil casi sólo en las expresiones umatrimonio civil y en los civilesn (o rguardia civilu). Para el estudio de la palabra habrla que tener en cuenta tanbién las expresiones civico y civismo (que suenan todavla a traducción), el empleo limitado y técnico de ciudadanta, y, por otra parte, el sentido de palabras afincs, como commnidad, que, pronunciada sin una calificación despierta aún hoy en el oyente la idea de comunidad religiosa. 
la autoconsciencia y autodeterminación de los españoles. Pero no quisiera leer demasiado entre las líneas.

Aún menos deja entrever nuestro cotejo acerca de la designación del protagonista de estas páginas, o sea del cortesano. El que quiera redactar la historia de esta voz ell español, y la de cortesanta, habrá de considerar el contenido del libro de Castiglione como fuente de enriquecimiento semántico de una palabra que ya existía previamente, como lo sugiere Terlingen en su estudio de los italianismos en español ${ }^{1}$, y que, además, tiene un contenido real algo distinto. Para captar esta diferencia en sus raíces, hay que empezar por la palabra corte, en cuya significación histórica, cultural, y hasta semántica, estriban las diferencias, muy fundamentales en la realidad de los hechos, aunque levísimas en el trasiego de Boscán. Corte, según la célebre definición de las Siete Partidas, indica el lugar "do es el Rey e sus vassallos, e sus oficiales con él, que le han cotianamente de aconsejar e de seruir, e los otros del regno que se fallan hi, o per honrra del, o por alcançar derecho, o por facer recabdar las otras cosas que han de veer con él, (II g, 27, ed. Madrid I807, II, 82).

Por la unidad de la monarquía española, Corte se identifica con el lugar de residencia del rey, que viene a ser la ciudad por antonomasia. Es, pues, sede del poder, y por ende escenario de ambiciones y de intrigas, a la par que centro urbano, con todos los atributos que se le acrecen de la antítesis con la sencillez idealizada de la vida campesina. Ejemplo proverbial de esto es la obra de Antonio de Guevara titulada justamente Menosprecio de corte y alabanza de aldea. Por otra parte, en el plural, cortes es el nombre que se daba a las asambleas convocadas por el rey en los distintos reinos de la Península. Para evitar confusión, Boscán a veces especifica: "corti» - "cortes de los reyes» (I I, 23 - 24; II 2, I5; 3 , I5; 3, I - III; I8, 30 - I30; 32, I2 - I46 y passim), y "cortes de los principes). (I 47, 6 - 9I; II 2, I - I09; 4, 3-II3 y passim). Pero, sobre todo, hay que tener en cuenta los matices peyorativos que en el siglo de oro adquiere la palabra corte: («más quiero fuera de la corte arar y sal-

1 Reproducimos aquí su comentario, que deberia puntualizarse mucho más, tanto en sus antecedentes medievales como en sus aspectos renacentistas: “Cortesano era desde hace siglos un substantivo genuinamente español, pero que, desde el momento en que Boscán tradujo Il Cortegiano de Baltasar Castellón, fué incorporado al español con nuevo valor semántico, es decir, de persona con modales urbanosn (Los italianismos en español, p. 40). De hecho, corlesano aparece como adverbio con el significado, al parecer, de uurbana y cortésmenten, ya en la Partida $V I J, 33,13$ (ed. cit., p. 726), y luego en los Cancioneros se codca con cortés para describir el habla y los nodales: "Respondiendo segund modo cortesuno", escribe Juan de Mena (Cancionero caslellano del siglo XV, NBAE, XIX, P. 218). 
varme que en la corte medrar y conclenarmen, escribla Antonio de Guevara en su Alabanza de aldea (Madrid I928, p. I73), y los defectos que se le imputan al cortesano, heredero además de todas las miserias tradicionalmente atribuidas al servicio de los grandes (recuérdense el Libro dc buen anzor, el Rimado de Palacio y las nuchas obras medicvales que reflejan este tópico). Justo unos años antes de la traducción del Cortesano

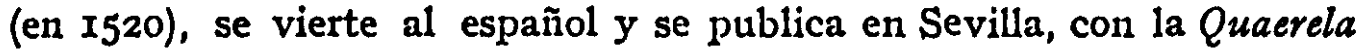
Pacis de Erasmo, el Tratado de la miseria de los cortesanos del que fue Pío II. ${ }^{1}$ La recrudescencia de la invectiva anticurialesca tendrá paralelos muy sonados en Italia, pero se le contrapone otra tendencia idealizadora que desembocó en el Cortegiano. En la Iralia del Cinquccento, tras de un Orlando Innamorato, pudo florecer la idea de la Corte, bien fuera sueño y añoranza caballeresca de un Boyardo, o modelo para academias de doctos. ¿Y en España? En las letras del siglo dieciséis se levantan, junto a la de Boscán, muchas voces discordantes. Sólo en sentido político, es como se reivindica el concepto de cortc. Gracián la concebirá como teatro de la política, palestra en la cual el hombre llega a afirmarse por su destreza y discreción, según los dictámenes de la ufilosofía cortesana».

La historia ulterior de los conceptos de corte y cortesano sólo entra en nuestro argumento en cuanto puede esclarecer la versión de Boscán. Pero en vista de que Boscán traduce corlegiano casi siempre con cortesano, no hemos registrado los centenares de pasajes donde aparece esta voz, y tampoco los que ilustran designaciones propias de la época en ambos países, como hombre de corte (omo di corte), hombre de bien (omo da bene), hombre honrado y de honra (omo onorato y d'onore). Dicho sea de paso, mientras que Castiglione usa de vez ell cuando el femenino, cortegiana, Boscán evita esta forma, seguramente por su acepción peyorativa, prefiriendo siempre dama o dama perfecta ${ }^{2}$.

1 .Nuestra intención -escribe ENEAs Silvio conjugando los consejos de su padre y su experiencia personal con una serie de tópicos tradicionales- es mostrar disputando ser locos los que se allegan a los principesn (fol. ij v). Una sola frase, que bien puede compararse con la de Guevara, bastará para indicar el tono de este escrito: "Por muchas tribulaciones entran los justos en la gloria, mas los cortesanos por muchas penas y fatigas trabajan de ganar el infiernon (fol. xn r.). Lo mús significativo para nosotros es la fecha en la cual el arcediano don Diego López tradujo el tratado anticortesano de Eneas Silvio para ilustración de sus contenporáneos.

2 Cf., por ej., corlegiana (II 99, 16) - tuna dauna perfectan (2 18); tuna perfecta dama, (III $4,5,227$ ). Sobre la palabra cortesana (que tambićn en italiano sufrio el iniswo deterioro), cf. J. E. Girr.ır, Propalladia (ed. I95 I III, 264-5). Bascán irnduce donna taubién con dama (I $6, x_{4}-32$ ), o con señora (I 4, 20-30; 10-38), y 
Sólo sugeriré que, para estudiar el desarrollo de la palabra cortesano (como sustantivo), habrá que tener en cuenta las otras voces con las cuales comparte el mismo campo semántico (en particular la palabra privado, cada vez más importante bajo los Iielipes ${ }^{1}$. Además, habrá que entresacar nucstro término sin desligarlo del contexto. Boscán, siguiendo muy de cerca las huellas de su modelo, nos habla de "buen cortesano", de "perfecto cortesano", y luego de "cortesano" a secas. ${ }^{2}$. La mayoría de las veces, tanto él como el propio Castiglione se sirven del sustantivo cortesano como de voz unívoca, evocadora de múltiples calidades y destrezas, y de oficios y perfecciones cada vez más elevados. El neoplatonismo renacentista busca la perfección de cada ser en su vocación peculiar; perfección que ha de resplandecer sobre todo ell los prototipos de la sociedad, en el príncipe, en el cortesano en la dama de corte.

Creo, pues, que la paridad de términos excluye toda comparación cntre los dos textos, pero podría servirnos la presencia o ausencia de calificativos junto a corlesano como criterio para comparar nuestra obra con otras del Siglo de Oro. Veríamos entonces que en éstas se nos habla del "buen cortesano", del "cuerdo cortesano", del "curioso cortesano", del "verdadero, honrado, bien criado", o del "prático cortesano", de cortesanos pulidos, gallardos, delicados o cuales fueran los adjetivos más en boga en cada generación y en cada autor ${ }^{3}$, siempre con el afán o la

a veces, amplla; «una donna (II 34,8 ), ‘una señora bien gentil dama y harto principal" (150). Otra designación muy frecuente es "domna di palazzon, y también "omo di palazzo (cf. I I6, 10). Boscán, que al principio traduce palazzo con casa (I 2, 23 y 24-28), siempre evita este término junto a donna y omo (cf. II 98, 27 y I 00, 9 -"dama», 217 y 219 ; II 99, 12- "dama perfeta", 218). En obras posteriores hallaremos "dama de palacio" (cf. el Despertador de cortesanos, ed. cit., p. 128). Recuérdese también la expresión "pajes de palacio» en el Diálogo que a sus miserias dedicó Lucas Hidda.co.

1 Véase cómo coexisten en el citado Despertador de Guevara (usepan los privados y sepan los cortesanos...., pp. 202-3, v. 9, p. 210); el privado sigue siendo cortesano (cf. pp. 56, I45, 236); pero de hecho se crea una jerarquia ("cuando a un cortesano... el privado le hablan, p. 62), y el cortesano se queda con todas las consecuencias que fluyen de su posición de inferioridad ("cortesanos y negociantes platican del privadon, p. 236). En Italia el cortesano no se queda tampoco por mucho tiempo en el pedestal donde le había colocado Castiglione; ya en 1534 el De re aulica, de Agustin Nifo, empieza a delimitar y reducir sus funciones.

2 Cf. respectivamente I 12, I5-39; ibid. 2 I; I4, I-42; 15, 4-44.

a Asl en el Desperiador: "cortesanos polidos" (9I), "el curioso c.* (ib.) «de c. cuerdo* (98). Gracián Dan'risco preferirá "práctico cortesano" (p. I73) y "gallardo cortesanon ( 3 30). BAI,TASAR Grachín nos habla de un adiscreto y avisado cortesanos (I 97), de "cultos cortesanos" (ibid. I 263), de wun gran cortesano" (I 237), pero omite todo adjetivo ("vivir entre los cortesanos") cuanclo enumera la "falta de verdad. y ala sobra de embelecosn de las cortes (ilid. 263). 
necesidad de distinguir al buen cortesano de otros muchos no tan buenos, y de salvar la cortesanía de los prejuicios que. ofuscan su nombre en la opinión de los escritores ${ }^{1}$ y en la boca del pueblo ${ }^{2}$.

Por otra parte, que la voz cortesano le fuera familiar a Boscán también en lo que tiene de descriptivo del trato social y sobre todo del liabla, lo demuestra el hecho de que le baja a las puntas de la pulma aun sin ser traducción literal del texto italiano. Estos pasajes de empleo independiente pueden echar alguna luz sobre la historia anterior de la palabra y confirmar lo que ya sabemos por otras fuentes ${ }^{3}$. Fijémonos en la traducción:

viver civile (IV 47, 36);

vivir con la orden que se suele tener en las buenas

ciudades $(367)$.

non so qual sia tauto inetto, che... andando a confortar uma madre, a cui fosse morto un figliolo, cominciasse a dir piacevolezze e far l'nrguto (II $6,1 \mathrm{I}$ ).

no sicnto yo quién fuese tan indiscreto que... cuando quisiese consolar uni madre que se le linbiese mucrto un hijo, por consolalla, se fundase en decille gracias y en liacer del cortesano ( I $_{4}$ ).

pigliar le cose come dette per gioco (II 32, 15),

tomar las burlas cortesanamente $\left(\mathrm{r}_{4} 8\right)$.

Alcuna volta, pensando per quello esser arguti e faceti, in presenzia d'onorate donne... si metteno a dir sporchissime e disoneste parole (II 36, II).

1 Véase, por ejemplo, cómo ALFONSO DE VALDEs entreteje el término cortesano en la condena de las falsas opiniones del vilgo: aal engañador [llaman] ingenioso, al dissimulador, mentiroso y trafagador, buen cortesano (Madrid, ed. Clás. cast., 1946), p. 47. Cf. también. la Epistola de Montemayor a Pagdn citada por Francisco Ióriz Listrada ell Estudios dedicados a Menéndez Pidal, vol. VI (Madrid 1956), pp. 397-40I.

2 Is significativa la actitud tan poco halagadora del refranero: "chumplimientos cortesanos, finos pero vanos"; "Palabras de cortesanos y p.... de fraile, todo es airen; "Raza de can, aluor de cortesano y ropa de villano no dura más que tres añost.

- Véanse los conjuntos de palabras afines con las cuales aparece cortesano en el Universal Vocabulario de ALFONSO DE PALENCIA (ed. Sevilla 1490): "Currosus es donoso, fablador, cortesanos (fol. I02 v); lepos... cortesano fablar y donoso razonamiento ell las burlas" (fol. 2.4x r); Corlesania: *iocus es dulce burla y cortesania $y$ palabras de rison (fol. $223 \mathrm{r}$ ). 
Acontéceles taubién a éstos que, por'mostrarse muy cortesanos y decidores, según ellos dicen, en presencia de mujeres de precio... se ponen en decir deshonestidades y desvergüenzas (153).

Sin querer extremar el valor de las tres citas, haré notar que en dos de ellas nuestro término se halla enıpleado esponténeamente $-\mathrm{y}$ una vez con un significtivo "según dicen»- en son de condena; cortesano se relaciona con una manera de ser, burlona y cliocarrera, nada compatible con la dignidad española.

Iis muy probable que esta afinidad entre la manera "cortesana" y la soltura de la lengua sea una de las circunstancias por las cuales cortesano fué desluciéndose, mientras que cortés y cortesía mantienen su valor encomiástico desde los primeros documentos literarios (como Elena y Maria), hasta el presente'.

También puede echar alguna luz sobre las vicisitudes semánticas y axiológicas de cortesano otro término no menos susceptible de menoscabo. Iin una ocasión vemos que Boscán desdobla el italiano "una corte» (III 5, 7) traduciendo: "en una corte o en otro lugar donde se traten cosas de gala" (229). Gala es palabra asentada en el uso ${ }^{2}$, y galanía expresa la gracia y elegancia de que han de preciarse los hombres de corte. Iin la versión, al lado de caballero, y para traducir gentilhomo (II II, 9), apa-

1 Cortés y cortesia tienen una pervivencia ininterrumpicla desde los primeros documentos literarios (BERCEO, Sac. 43. Apolonio 423 a. Libro de Buen Amor 1549 c. 1687 d). I, a cortesla es alabada en las obras doctrinales (Flores de filosofia en Dos obras didicticas [Madrid 1878], p. 47, Caballero Cifar [ed. WACNER, Anu Arbor 1929], p. 294-295), y, por supuesto, en los Cancioneros, donde forma el núcleo miswo del amor cortés (Cf., por ej., el comprensivo ensayo de O. H. GREEN ،Courtly Love in the Spanish Cancioneros", Publications of the Modern Language Association of America, LXXIV (1949), pp. 247-30r. Además de la aparición de la palabra habria que estudiar las vicisitudes de su contenido, bien sea que este llegue a las propias raices del ser o sólo roce la superficie de los modales de la convención social (para el italiano, véanse Al,Do VArLONE, La cortesia dai provenzali a Dante [Palermo 1850] y los ensayos del mismo autor recogidos en el opúsculo, Corlesia e nobilla nel Rinascimento [Asti 1955]. In cuanto a la relación formal de cortesano y cortés, nos limitamos a observar que será típico del chiste barroco el contraponerlos. Juega con las dos palabras, por ej., SAL,AS BARIBadiLLo en el título de su novela dialogada, El Cortesano descortés, y el en texto cle la misma (iredúzcase V. al gremio de los caballeros corteses..., en Dos novelas [Madrid 1894], p. 62).

2 Véase, por ej., el ‘Cantar que fizo el Marqués de Santillana a sus Fijasv: «demuestran mayor galan (Canciones y decires [Madrid ed. Clás. cast., 1942], p. 220). Notaré que galán no se halla en las obras de tono más serio, que representan la genuina idealización hispana, como las Generaciones y semblanzas y Los claros va$r$ ones de Castilla. 
rece el "buen galán" ( $(2 \mathrm{I})$, y otras veces también asoma esta palabra sin estar sugerida en la fuente italiana ${ }^{1}$. Galán no ha sido objeto de un estudio comparable al que se ha dedicado a su homónimo francés ${ }^{2}$. Es muy posible que en el pasaje que acabamos de citar se exprese el sentido de valor y gallardfa (que entraña el concepto de caballero), y que fué propio de la palabra francesa en el mismo período 3. Sin embargo, galán no entró nunca en ninguna combinación comparable al francés galant homnne o al italiano galantuono, sino que se relacionó y sigue relacionándose sobre - todo con la apostura del traje y la cortesía hacia las damas ‘. Más tarde el grupo gala-galanta-galano se ampliará, con la admisión (no sin influencia italiana) de galante, galantear y galanteo, voces todas ellas del "lenguaje de estrado ${ }^{5}$, cuyo uso se reforzó quizá gracias a la difusión del Galateo español de Gracián Dantisco * Conclúmos, pues, que la cercania

1 Castiglione usa galante, por ej., en las cartas: $\mathrm{E}$ '1 figluolo del Papa era molto galanten (cf. Le lettere del conte B. C. [Padua I 769-7 I], col. I, p. 4); igli oratori del Re di Portogallo sono venuti a dar la obbedienzia al Papa, molto ben in ordine e galanti" (ib., p. 21 ).

- Cf. 15. 'MunaU, 'Galant', ein Beitrag sur fransosischen Wort und Kullurgeschichto (l'rankfurt 1936), trabajo del que sólo he podido ver la recensión de H. RIIEINHLLDLR ell la Zeitschrift fïr romanische Philologie LVIII (1938), 408-410.

- Cf. I. GAMIILSCHLG, Elymologisches Worlerbuch der französischen Sprache (Heildelberg 1928): 'galant..., bedeutet in I6. Jhdt. 'kräftig', 'fühig', 'tüclıtig', wit sichtbarer Anlelnnung an gaillards.

- Muy significativa ine parece la definición de Covarrubias en su Tesoro (I6II): Galdn. El que anda vestido de gala y se precia de gentillombre, y porque los enamorados de ordinario andan muy apuestos para aficionar a sus damas, ellas los llaman sus galanes, y comúnmente dezimos, 'Fulano es galdn de tal daima'. - Esta explicación corresponde al tipo del cortesano que habla ido formándose en la tradición doctrinal. Véase el capltulo de Eneas Silvio aDe los plazeres y deleites, en su citada obrita: Andan ricamente vestidos y traen coletas muy peinadas, porque justan y juegan cañas, cantan, dançan, y siempre andan alegresı (fol. 6 r). A vueltas de lo cual asegura el futuro pontifice que ala dama no se confla dellos por alabanciosos, parleros, no constantes y enamorados de muchası. (Ibid.)

- Cf. el texto de Lope de Vega citado por HERRERo Garcfa en Estimaciones literarias (p. 299): „Don Félix festejaba a su hermana, que es lo que ahora llaman galantear entre los vocablos validos; que cada tiempo trae su novedadı, y tambiéll lo que Pérez de Montalbún hace decir a uno de sus personajes: „Cortésmente, que esto llaman en la corte galanteo (ib.).

- Ińn chya traducción hallamos varias veces galanteo (de Galeazzo) no sólo sustantivado, sino desempeñando el papel de adjetivo (Cf. Icuando el gentilhombre galateo,, p. I05). También lo usa asi IOOPE DE VEGA en su soneto, pero como alusión al nombre del autor: iLlámase el cortesano que la trajo..., Gracián, galán, gallardo, Galateo (ed. cit., p. 2). No sé que la palabra en esta forma haya teniclo wás difusión, y nada dicen de ella los diccionarios. 
semántica de galán y la sinonimia de las parejas "damas y cortesanos" $\mathrm{y}$ «damas y galanes» pudo muy bien contribuir a la parábola descendiente del concepto de cortesano, dando mayor peso a las cualidades exclusivamente mundanas y ornamentales que le habia atribuido Castiglione.

Pero cabría entrar en la historia de cortesano también por otro lado. $A$ algunos les ha parecido poco sincera la primacía que en el Cortegiano se le brinda a las armas, $y$ se ha tildado de anacrónico el intento de reavivar el ideal caballeresco de la Iidad Media en el ambiente renacentista de las cortes del Cinquecento. De hecho, tenemos a veces la impresión de que el concepto de la cortesanía, a fuerza de extenderse y abarcar demasiado, se le deshace a Castiglione entre las manos.

Si nos fijamos en los vocablos, vemos que cortegiano en el original se codea con otro término, portador de faustos pasados, cavaliere, y que, junto a la cortegiania, salen a relucir las obras y ejercicios "della cavallerian (I 3, 39). No hay que olvidar que el mismo Castiglione fué armado caballero, y que participó activamente en hechos de armas.

Aún más frecuente es un término, no nuevo en italiano ${ }^{1}$, pero anunciador de otra era: gentilomo. Se ha dicho que la obra de Castiglione atracría a más lectores si se hubiese titulado Libro del Gentilomo. De hecho, cortegiano se halla entre dos términos, cavaliere y gentilomo. Como Jano bifronte, mira con su faz de caballero hacia el pasado, y, con su cara de gentillombre, hacia el futuro. Ahora bien, aun sin haber registrado puntualmente todas las ocurrencias de dichas voces, creo que puedo resumir así, en forma esquemática, la transformación que se produce en el translado al castellano:

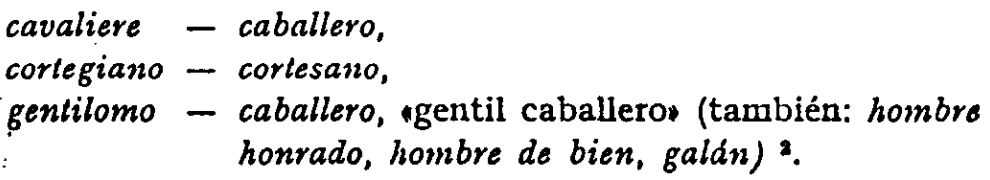

1 Para citar un ejemplo concreto: en la versión del De regimine principium, en el capitulo sobre las costumbres de los nobles $(I 4,5)$, hallamos que nobiles se traduce con ugentili uomini, Del reggimento de' principi di Egidio Romano. Volgarizzamento trascritto ne MCCLXXXVIII, ed. de F. CoRAZZINI [Florencia 1858], p. $\times(9)$.

- Cf., para el trueque gentilomo-caballero: I 3, 32-29: 5, I-3; 17, 8-47; 20, x6-52; $21,23-53 ; 27,29-61 ; 42,16-84$ [dicho de franceses e italianos] ; 43, 26-86, etc.; 4caballero muy honrados (II 32, 3-I47); un caballero tenido en buena reputación, (50, 14-48), un caballero y buen galán (II II, 19-12I). También traduce gentilomo-hombre honrado (I 20, 18-52); y hombre de bien (I 22, 22-54; II 22, 33-I36). 
Si Boscán hubiese emprendido una obra original, en vez de haber traducido del italiano, me figuro que habrla escrito un doctrinal de caballeros en la tradición de los tratados de Ramón Lull y de Alfonso de Cartagella.

Por otra parte, al subrayar este contraste, no quiero restarle importancia al papel que aun en el Cinquecento, 0 , mejor dicho, justamente en el Cinquecento, desempeñó el término cavaliere tanto ell las costumbres como en las letras italianas ${ }^{1}$. Fué del italiano de donde pasó cavaliere a Francia y a Inglaterra, muy ligeramente adaptado a la fonética de sendos idiomas, para desenvolverse luego ell cada país de modo algo distinto ${ }^{2}$. Además, İspaña e Italia contribuyeron ambas poderosamente a mantener en vida la materia caballeresca, trasfundida en obras de extraordinaria difusión. Pocos asuntos hay en la historia de la literatura comparada tan sugestivos como el de los ciclos bretones y carolingios, con sus múltiples ramificaciones y variantes: reino abonado para los que gusten de buscar fuentes. Para la evolución de nuestro término, sin embargo, nos interesaria más captar la actitud que en versos y novelas se revela hacia un ideal de antaño, encarnado en un mundo imaginario, pero riquísimo en contenido ético y religioso. Aquí nos linitaremos a afirmar que en lispaña la norma caballeresca, a pesar de todas las exóticas aventuras de los que la van llevando por el mundo, no se desarticula nunca totalmente de la vida real y de la moralidad vigente ${ }^{3}$. No es una

Nótese cómo al sustituirse caballero por gentilomo asoma también la antitesis caballero-escudero:

le donne cominciarono a ridere, e dir che costui era indegnissimo d'esser chiamato gentilomo (III 7I, I5).

Todas aquellas señoras entonces comenzaron a reir mucho y a decir que este tal no debiera de ser caballero, sino algún escudero muy ruin (305).

1 Sobre cavaliere y las normas del honor en Italia, cf. entre otros F. R. BRXSON, The Point of Honor in Sixteenth-Century Italy (Chicago r935); sobre la iufluencia de los tratadistas italianos de la houra, cf., por ej., D. C. SrUART, ،Honor in Spanish Draman, The Romanic Review I (19ro), p. 253 y ss. En cuanto al concepto de caballeria en las letras, véase, por ej., el libro de AzzoL,INA, $I l$ mondo cavallevesco in Boiardo, Ariosto e Berni (Palerwo 1912).

2 Véanse las breves observaciones de M. PrAz, *The Italian Element in Einglish" en Essays and Studies XV (1929), 28.

3 Es muy revelador en este sentido el libro de J. RUIZ DE CONDE sobre El amor y el matrimonio secreto en los libros de caballertas (Madrid 1948). Después de un exordio didáctico-religioso con el Caballero Cifar, aun en la materia caballeresca se busca un compromiso entre el concepto del amor cortés (del que eran susceptibles tan súlo las clases mís altas) y la moralidad arraigada en el pueblo, y para no 
de las menores paradojas de la historia de Esspaña que de ella nos viniera la mejor crítica de la novelas de caballerla, junto con la renovada afirmación del ideal caballeresco: en un mundo que le hostiga con sus realidades prosaicas y contingentes, don Quijote pierde el seso tras de la andante caballería, pero parsonifica en sus aspiraciones y en su conducta la ejemplaridad trascendente del caballero cristiano.

Si las novelas caballerescas en España y los poemas heroicos en Italia contribuyeron a enriquecer el contenido semántico de caballero y cavaliere, habrá que tener en cuenta la difusión de dichas obras, que en ambos países tuvieron un atractivo universal ${ }^{1}$, pero que en Italia llevan una relación particularmente estrecha con los ambientes cortesanos. En Ferrara, en Mantua, en Reggio, en Bolonia, la sociedad aristocrática gustaba de la recitación de octavas caballerescas, y veía reflejado en ellas su propio ideal de "valor y cortesía". Para alimentar la afición literaria de las cortes y para recreo de damas y cortesanos, la fantasía de los poetas no se cansó de entretejer los múltiples hilos de la tradición caballeresca, poniendo de manifiesto al mismo tiempo lo anacrónico e incóngruo de los paladines de antaño.

Así los mismos que ensalzan la caballería, la van relegando a un mundo distinto. La sátira italiana, ya se exprese en la fina ironía de un Ariosto o de un Boyardo, o en la risotada de un Pulci, bien sea puramente literaria o también política (con Machiavelli, por ej.), acabó con la caballería y con el cavaliere. No es ésta la ocạsión apropiada para entrar más adentro en el proceso clevastador, consecuencia inevitable del ofuscamiento de la Iglesia y del Imperio en la mente de los italianos. Si nos fijamos en el uso actual, vemos que en Italia (después de la lluvia de títulos honoríficos que inundó el país de "cavalieri» antes de la segunda guerra mundial), cavaliere ya no se usa casi más que para ponderar la cortesía hacia la mujer. No así en la Península Ibérica. En España ser "un caballero» o "todo un caballero" supone una afirmación de la personalidad total del varón, que no admite reservas ni ironías.

No queremos olvidar la crisis por la cual pasó también aquí el concepto de hidalguía (y por ende también el de caballero) en la época barroca,

ofender el sentido religioso y moral y salvaguardar el principio del honor se busca el recurso del matrimonio secreto. Sólo en el Palmerin de Inglaterra percibe la autora los primeros sintomas de descomposición, precursores del barroco.

1 Para Italia sigue siendo básico el libro de $\mathrm{F}$. I'orlisno, Il poema cavalleresco (vol. 7 de la Storia dei generi letlerari ilaliani, Milán, s. d.). En la época en que escribla el autor (1904). Sicilia conservaba aún vestigios de materia carolingia, preservada por los cuentistas ambulantes y en los teatros de marionetas. Aún hoy he visto pintados en los carros sicilianos escenas de paladines. 
cuya literatura está marcada justamente por la tensión entre los extremos del pundonor en el drama y el rebajamiento de la honra en la sátira. Sin embargo, cuando un escritor cono Salas Barbadillo, quien tuvo también sus partes de satírico, quiso dar a sus contemporáneos un trasunto novelado del Cortegiano, escribió, bajo el significativo título de El caballero perfecto (I620), la bibliografía idealizada de un "católico caballero" en cuya persona se une la tradición caballeresca medieval con el espiritu de la Contrarreforma. ${ }^{1}$.

Es del todo natural, pues, que Boscán echara manos con frecuencia del concepto de caballero, de origen germánico pero perfectamente amalgamado con la tradición española, símbolo, como el que más, de la continuidad cultural hispana. Desde que la Reconquista habia ido sustitu yendo la dominación cristiana por la mozárabe, y empieza a hablarse e n los documentos de caballarii y de pedones (cf. Mayer, I 34), campean caballeros en la escena española, bien sean éstos del campo o de los centros urbanos, armados de entre la nobleza (ricoshombres, infanzones, hidalgos), o trafdos de las villas y cittdades (caballeros villanos, y caballeros cibdadanos $^{2}$, u honrados). Cambian las circunstancias históricas, se han debelado los infieles y distribuído la tierra; las grandes órdenes militares pierdell su razón de ser; pero se sigue empleando el mismo título. Aún hoy caballero, a pesar de todos los anacronismos que arrastra consigo, apunta a las cualidades más apreciadas por la raza hispana: el desprecio de la muerte y el sentido de la honra. Por el espiritu individualista que le informa quizá sea prenda de que Iispaña llegue a sustraerse a la nivelación

1 Y, dicho sea de paso, ell una obra tan rica en adjetivos, cortesano no aparece ui una sola vez como atributo del protagonista.

- Cf., por ej., el documento por el cual Alfonso X concede tierras y exenciones a los caballeros fijosdalgo, a los caballeros cibdadanos y a los peones ique poblasen en Requenav reproducido por E. DE Hinojosa en Documentos para la Historia de las Instituciones de León y de Castilla, siglos X-Xrrr (Madrid 1919), p. Ioz. Sobre el tema de la caballeria en las Partidas, cf. las apuntaciones de J. BENEXTO PĹREZ en Los ortgenes de la ciencia polttica en Espaĩa (Madrid 1949), pp. 331-334; es interesante la nota sobre las posibles, influencias italianas (especificamente de Bolonia). No conozco el libro de J. M. LACARRA, Ideales de la vida en la España del siglo XV: el caballero y el moro (Zaragoza 1949). De la caballerla española sehace mención en todos los estudios generales sobre la institución caballeresca, y se le dedica un capitulo aparte, desgraciadamente algo flojo, en el tomo compilado por 15. Prastage, Chivalry: A Series of Studies to Illustrule Its Hislorical Significance and Civilizing Influcnce (Nueva York 1928), pp. I09-I40.

I'ara una evaluación puesta al día y con auplias referencias bibliográficas, cf. el estudio de A. García GaIr,n, Las Instituciones sociales en España en la alla Edad. Media, siglos vur-Xir. Madrid 1945; sobretiro de la Revisla de Esludios Polticos. 
de costumbres e ideas que está invadiendo tan rápidamente el resto del mundo occidental.

Otras circunstancias más inmediatas podrían citarse aquí, como la tantas veces señalada ascendencia del ideal caballeresco en la segunda mitad del siglo $x v$, que vió el túltimo esfuerzo armado contra infieles. Pero, volviendo a nuestro contraste inicial de gentilomo-caballero, no hará falta notar que el término gentilhombre no ha llegado nunca a desempeñar en España un papel comparable con el de gentilomo en italiano, gentilliomme en francés, ${ }^{1}$, y especialmente gentleman en el mundo anglosajón ${ }^{2}$. No es que la palabra no pudiera arraigar en Castilla, donde también hallamos mención de infanzones lindos (cf. Mayer, I 66). E1 castellano pudo haber tomado el término de Cataluña, donde se nos habla de gentils omens ${ }^{3}$, y de hecho lo hallamos esporádicamente en prosas medievales ; pero su adopción y propagación fué principalmente para la designación de cargos palaciegos ( $y$ así Fernando de Aragón tuvo su cuerpo de gentiles hombres ${ }^{5}$, y más tarde hubo "gentileshombres de la casa",

1 Cf. P. Tor,Do, we Courtisan dans la littérature française et ses rapports avec l'oeuvre de Castiglione Herrig-Archiv (r900), vols. CIV y CV, y M. Zirno, "Castiglione e Montaigne (gentilhommen). Convivium (1938), 56 -60.

2 Cf., W. Schrinnisr, Castiglione und die englische Renaissance (Berlín 1939), sobre todo la conclusión, "Cortegiano und Gentleman", pp. 150-16r. Esta es una monografla excelente y superior, en mi opinión, a las obras más generales que le han precedido, como la de R. KisLSo, The Doctrine of the English Gentleman in the Sixteenth Century (Urbana: University of Illinois Studies in Language and Literature, 1929), en cuyo segundo capitulo se hallarán algunas observaciones sobre gentility y nobility. En español pueden verse algunos apuntes algo desligados en el librito de A. Garcfa Valdecasas, El hidalgo y el honor (Madrid 1948), pp. $69-83$.

- Cf. la Obra de Mossen Sent Jordi e de cavalleria en P. DE BoparuLI, Colección de documentos inéditos del Archivo General de la Corona de Aragón (Barcelona I853, VI, 35-36.

- Io he hallado en el Doctrinal de Principes de Diego DE VAlera junto a caballero (cf. los fols. 38r, 63v, 63r y otros lugares del MIs. 12.672 de la Biblioteca Nacional, donde se aplica tanto a extranjeros como a españoles; pero no hay que olvidar que este prócer, ya en los umbrales del Renacimiento, tuvo una existencia muy cosmopolita.

- Cf. las Noticias acerca de la instilución del cuerpo de gentiles hombres por don Fernando el Catolico en I512, LXXXII (1923); 17-10. Fn el privilegio latino se los llan1a gentiles homines (p. I8), en las ordenanzas castellanas se les cla el título de Gentiles hombres de la casa real y Caballeros de la guarda de su real persona (p. 28). Obsćrvese en este dociunento cómo al principio se nos habla de caballeros y fijos dalgo, y cómo luego la designación distintiva (e innovadora) de gentiles hombres entra a formar parte del contexto. 
"de la cámaran, y ude la bocan) ${ }^{1}$. Gentillıombre a secas se dijo además de italianos, alenianes y franceses, mientras que los españoles seguian siendo caballeros ${ }^{2}$.

En las fuentes literarias anteriores a Boscán no siempre es posible decidir si se nos habla de un gentilhombre o de un hombre gentil ${ }^{8}$. En nuestra versión hallamos gentil hombre (aun independientemente del original) escrito en dos palabras, y desempeñando gentil su pleno papel de adjetivo, bien sea en aposición o como predicado". Véanse algunos ejemplos:

Il Cortegiano... abbia da natura non solamente lo ingegno, e bella forma di persona e di volto ... (I 14, 46),

nuestro cortesano... tcnga buen ingenio, y sea gentil lionbre de rostro y de buena disposición de cuerpo... (44);

dianzi dicesti, clie questo nostro Cortegiano aveva da esser dotato da natura di bella forma di volto e di persona (I 19, 2),

arriba dixistes, que este nuestro cortesano convenua que fuese gentil lombre de rostro y de cuerpo (50);

1 I.os cargos de "Gentilcs lombres de la boca" y "Gentiles hombres de la casa" se hallan descritos ell A. RODRfGUez VIrLA, Etiquetas de la Casa de Austria

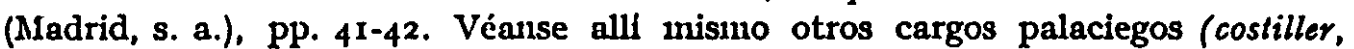
mariscal de logis, furrier, portero de la maison, grefier, sumiller, sausier y otros, que revelan la contaminación del lenguaje de corte con la terminologla extranjera - francesa - al introducirse elı Lspaũa la etiqueta borgoũona).

2 Asl, por ej., en el Galateo español se nos habla de ralgún gentilliombre veneciano (ed. cit., p. 26), de uu gentilhombre romano (p. 49), y hasta de un gentilhombre, en Valladolid.... (p. 109); gentilhombre campea en todo el libro en cuanto es adaptación, a veces hasta servil, del italiano. Pero si luego ojeamos la Novela del gran Soldin interpolada entre los capitulos doctrinales, vemos que alli a los hombres principales se los llan1a "caballeros" (cf. las pp. I 24, I32, 135).

2 Véanse, por ej., en el Cancionero de Juan Fernández de Ixar (Madrid 1956), los versos siguientes: «Si todo rey d'este nonbre / Alfonso resplandesçio. ¿que tal seria en gentil onbre..." (I, 304); "Eñ boca de gentil onbre/ mal está la villania" (II, 474). Del mismo modo como se describe al hombre, se describe tambiéu su presencia (sla primera muestra es / del onbre gentil presencian (I, 9), y su figura (asu linda gentil figuran I, 24).

- Cuando gentilhombre adquiere papel de cindadania de hombre compuesto le vemos aparecer como predicado, y con su artículo ("como era un gentillombre" Galatco, 10), como sujeto ("Cuaudo el gentilhombre dice alguna agudeza" ib., 105), como complemento con su adjetivo (no le aconsejarla yo al práctico gentillounbre...., ib., 10.1). Sölo el plural sigue delatando la composición que le ha dado origen: Ahonranclo en su casa a los gentiles hombres pasajerosı (ib.). 
per troppa voglia d'esser tenuto bell'omo ( $[23,6$ ), de pura codicia de ser tenido por gentil hombre (55):

un gentilomo... di assai gentil aspetto (II 34, 5), un caballero... harto gentil hombre ( 50 ):

la gentilezza (III 59, I0) - el ser gentil lombre (293).

Notamos lo mismo con respecto a dama: «una valorosa donna in una nobile compagnia" (I I7, 3I) - «una gentil dama... delante de otras muchas" (48).

En el siglo diecisiete, aun cuando gentilhombre ya ha entrado en el uso como nombre compuesto, siguen percibiéndose sus dos elementos. In el auto sacramental De los Cantares, por ejemplo, le hace decir Lope a la Esposa:

¿Quićn oyó tan dulce nombre?

¡Qué linda capa encarnada!

¡Oh, cóno estás gentil hounbre! ${ }^{1}$

a lo cual contesta Cristo, con cierta ironfa, "El gentil hombre me agradan. Por su ambigüedad (gentil-pagano y gentil frente a judio), como también porque gentil es el término consagrado de la ironía (cun nobile adulatore» II I8, I3 - «11n gentil lisonjero» I29), se explican los equívocos de la novela picaresca, y los juegos de palabras tan frecuentes en Cracián y otros autores ${ }^{2}$. Estos chistes no serían posibles si estuvieran fundidos los dos elementos como lo están, por ej., en gentleman.

Podemos concluir esta parte diciendo que en el original cortegiano (junto con omo di corte, di palazzo y cavaliere) gravita hacia gentilomo, mientras que en la versión la equivalencia se limita a cortegiano-cortesano. Gentilhoinbre, en cambio, no llega a desplazar caballero del puesto central que ocupa en la tradición lingiiística y en la mente del traductor.

Acaso sea éste el lugar más apropiado para mencionar la distribución de nobiltà entre varios conceptos. Para Castiglione nobiltà es, en sentido específico, "nobleza de linaje», como traducirá Boscán (I I4, 6-42), condición que de hecho considera imprescindible para el cortesano: nobile ("re di generosa famiglia" ib. I) ha de ser el hombre de corte para lucirse: nobilissima, la sangre ( $\mathrm{I}$ 5, 6); nobili son los caballeros que sientan el ejemplo con su conducta $(\mathrm{I} 3,44)$. Pero, al lado de esta alcurnia de nacimiento, hay otra, que el lenguaje subraya a cada paso: nobili son los in-

1 Piezas maestras del leatro leologico español (Madrid r946), I, I29.

2 Cf. El Criticón (ed. de I'iladelfia, 1938-40), II, I 18, 183, 31 5; III, 132-3, 234. 
genios (I 5, II, 37, 79; 46, 30) y los espíritus (II 4, 8); los escritores (I 32, 26; 36, I3) y los pintores (I 52, 2I); nobili son los ejercicios (I 22, II), las armas ( $(42,3)$, los estudios ( $I$ 42, 2I). En otras palabras, nobile (junto a chiaro) es sinónimo de excelencia y sirve a cada paso para entresacar a los hombres y las cosas, proyectando sobre ellos la luz de los valores que los humanistas del Quattrocento no se hablan cansado de ensalzar ${ }^{1}$.

Ahora bien: nuestro traductor conoce y usa las palabras noble, nobleza (y ennoblecer), que el castellano hereda del latín clásico y medieval. Pero no se puede decir que éstos sean términos claves de su vocabulario, como lo son del de Castiglione. Basta leer unas cuantas páginas para percatarnos de que Boscán separa la nobleza del nacimiento de todas las demás excelencias, y para la primera prefiere la expresión univoca linaje (cf. I I4, 46 - 44) y las locuciones ade buen linaje" (I I4, I - 42; I7, 8-46) y ude gran linaje» (ib. I2), o los sinónimos y afines ude alta sangre" (I 3 , 45 - 29; I4, 6-44; 6 6, 3-45), wde buena parter (ib. I4-43), ude alto precio" (II 4, 8-II3), "principal» (D 2, 49-I7), "cle calidad" (I 3I, 35-67), "honrado" (II I0, 3-I2), "generoso" (I 49, 9-94).

Pero ni nobilissimi costumi" (I 42, I7) son para él "grandes virtudes" (84); "grandes" (II3) o usingulares (3I) o ualtos y maravillosos" (78) son los ingenios; "bueno", el ejercicio (54); "honrado y principal», el estudio (84); "famosos", los pintores (98), "excelentes", los autores (90). En otras palabras, hay una división más o menos consciente de lo que en el original era denominador común entre el linaje por un lado, y la prestancia del espíritu o la excelencia de las cosas, por otro.

Pero prosigamos el tema de este capítulo, considerando al cortesano en su atuendo exterior y en el marco de las habilidades y destrezas que le atribuye Castiglione. Empezando por el traje, consignaremos de paso

1 Piéusese en los tratados de Coluccio Salutatri ell el De nobilitate de BracioLIRI, el De vera nobilitale de Pratina, la Epistola de nobilitate del Garateo, y los tratados De dignitate de ManE'rTr y de PrCo DI LA MrRANDOL, y ell otros muchos escritos, que ensalzan la nobleza adquirida por el ejercicio de las letras y de la virtud. Hueiga recordar que en Italia el cambio contenido y la sustitución de un concepto de nobilld adquirida por el de nobiltd ligada al nacimiento, es efecto de una serie de circunstancias históricas, y especialmente de la evolución social de la burguesía. En el concepto de nobiltd, primordial para la comprensión del Renacimiento, han insistido casi todos los estudiosos desde J. BURCKIAARDT hasta E. WALSER y E. GARIN, véase también el trabajo de C. DE FREDE, iIl concetto umanistico di uobiltà. Pomponio Leto e la sua fauniglian, Annali della Facolta di Lellere o Filosofia dell' Universita di Napoli (1952), 205-226, y la citada monografla de A. VAL, I,ONLs, particularmente las pp. 47 y ss. 
ciertas equivalencias de terminologla para la designación de las prendas fundamentales:

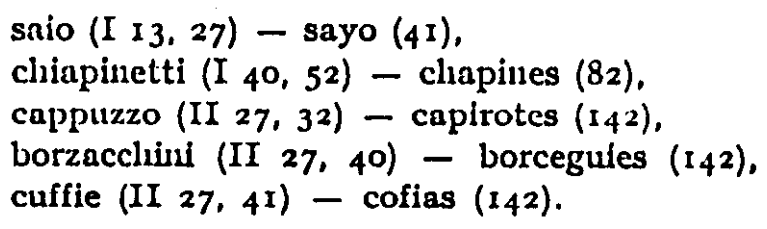

Boscán, aparte algunas peculiaridades del traje como "le maniche a comeo" (II 27, 3I) - "mangas anchas» (I42), tiene a su disposición los elementos necesarios para reproducir las descripciones del original. Véase, por ej.:

gli abiti festivi, trinzati, pomposi e superbi (II 27, I4),

los vesticlos lozanos y le fiesta, bordados y acuchillados, pomposos y solscrbios (14 1 ):

un gentilomo con una robba adosso quartata di diversi colori, overo con stringhette e fettuzze amnodate e fregi traversati (II 27, 24), [tante

un caballero con una ropa de diversos colores, y con un sayo lleno de cuchi$y$ de cintillas $y$ de tiras y de ribetes ( 142 ).

[lladitas

Por tanto, si en otros lugares vemos apagarse el brillo de "ricchissimi drappi d'oro" ( 2 2, $26-28$ ), es a cierta pereza y obtusidad a las que hemos de atribuir su desaparición, o a cierta cortedad verbal y aversión hacia los conceptos abstractos, como en este otro trozo, donde el traductor sustituye un ejemplo concreto a la descripción genérica de Castiglione:

Non vi pare che grandissima grazia tenga, se ivi si vede con una certa donnesca disposizione leggiadra ed attillata nei suoi chiapinetti di velluto e calze polite? (I 40, 50).

¿No habéis vosotros mirado cuando acaso acontece que yendo una dama por la calle o estando en otro lugar burlando, se le descubre un poco el pie o el chapin descuidadamente, si entonces se ve bien aderezado lo que uuestra, cuán bien parece? (82).

- Mucho mayor es, en cambio, la puntualidad y precisión con que Boscán traduce las referencias al ejercicio de las armas, que Castiglione coloca en primer término entre las habilidades del hombre de corte: 
intenda le querele e differenzle che possono ocorrere, e sia advertito nei vantaggi ( $2 \mathrm{I}, 3$ ),

entienda... lo mecesario en carteles de batalla, y que sepa hacer bucia su querella y aventajarse en los puntos que liubiera ell ella (52) 1 .

Para describir lances y desaflos tiene el castellano toda una terminologla propia, de la que Boscán mos da alguna muestra (uuscire de' termini" [III 37, 6] - napartarse de la telan [304] ${ }^{2}$. En cambio, no penetra en la traducción una voz común a los países de Europa en la terminologla caballeresca y del honor, rimprochio (rreprochen) ${ }^{3}$, y quedan sustituldos por otros dos tecnicismos bélicos: cannonate (I 2I, I5) - «tiros de pólvora" (53), y "scoppio di bombarda" (II I6, I6) - "la pelota del escopeta" (I27) ${ }^{5}$.

Si el arte de la guerra deriva de Italia una parte considerable de su terminologla ${ }^{6}$, aún más le deben la literatura, la música y las artes figurativas. En nuestra versión, poco habrá que decir de la alabanza de

1 Cf. tb. I 2I, 13-53. Huclga subrayar que punto, tanto en italiano como el espaniol, se halla muy al centro del vocabulario del honor. In español punto es palabra mins prolifera; plénsese en pundonor (ct. GiLlLE, Propalladia III, II3-4), y en puntual ("Caballero puntualo), en buen sentido y malo (sobre todo en los sat1ricos como Quevedo y Salas Barbadillo).

- Cito todo un pasaje para que se puedan apreciar los parecidos y las diferencias:

E perché de gli italiani è peculiar laude il cavalcar bene alla brida, il maneggiar con sagione massimamente cavalli asperi, il correr lance e'l giostrare, sia in questo dei migliori italiani; nel torneare, tener un passo, combattere una sbarra, sia bono tra i migliori franzesi; nel giocare a canne, correr tori, lanciar aste e dardi, sia tra i spagnoli eccellente (I 21, 32).

De sucrte que en cabalgar a la brida, en saber bien revolver un caballo áspero, en correr lanzas y en justar, lo haga mejor que los italianos; en tornear, en tener un paso, en defender o entrar en un palenque, sea loado entre los wís loados franceses; en jugar a las cañas, en ser buen torero, en tirar una vara o echar un lanza, se señale entre los españoles (53-54).

- Sobre rimprochio (auomini di riproccian) cf. B. Croce, La Corte spagnola di Aljonso d'A ragoñ in Napoli (Nápoles 1894), p. 24.

- La voz bombarda, sin embargo, ya se halla en el marqués de Santillana, según TerLingen, op. cit., p. 205.

- Cf., Terr.ingen, 206-7. Isste italianisuo ya debió de entrar en el español del siglo XV (GILI.ET, Propalladia III, 422-3; cf. ibld., 463, y en la página siguiente, la compendiosa historia de la actitud hacia las armas de fuego).

- Véanse los capitulos que 'l'serr,INGEN dedica a la vida militar, pp. 8x-86 y 173-222. 
las letras ("que llaman de humanidad", I 43, 8-85), por ser casi idéntica la terminologia ${ }^{1}$, dentro de la acostumbrada diferencia de tono ${ }^{2}$. Notaremos, sin embargo, que en estos capitulos, Boscán acepta por dos veces el calificativo de divino ( 85 y 90 ), título del que fué tan pródigo el Renacimiento italiano para con los literatos y artistas ${ }^{3}$. Otra peculiaridad muy de Italia fué la de destacar a sus hijos con el artículo deterninado (aqú realmente demostrativo). Nuestro traductor se refiere él también al Petrarca, al Policiano, al Mantegna. Lo mismo hicieron otros escritores casteLlanos antes y después de Boscán, consagrando, en cierto modo, la fama y ejemplaridad universal de los grandes modelos italianos.

De las artes que ensalza Castiglione, la primera, en orden de dignidad, es la música. En el vocabulario musical también hay que subrayar equivalencias. consonanzie [I 28, 2] - consonancias [6I]; dissonanzia [ib. 5] disonancia [ib.]; armonie- armontas [I 37, 3I-76]; "una segunda y una sétima" ]I 28, 4-6r], a la par que circunlocuciones como las ocasionadas por melodia y modulazioni:

quella superficial melodia che si sente ( $\mathrm{I} 47,32$ ),

aquella dulzura de son que nos da en los oldos (92);

1 Añadimos los términos soneto, que Boscán, por supuesto, traslada sin vacilaciones (I 9, 39-36), madrigal y novela. Este sólo lo emplea cuando se trata de las de Boccaccio (II 49, 14-I69).

- Véase, por ej., la paráfrasis por la cual Boscán vierte una expresión muy clásica (la de monumenta litterarum):

quanto amava e venerava i sacri monumenti delle lettere ( $\mathrm{I}_{46}, 3 \mathrm{I}$ ), cuánto era el amor que tenía a la memoria que en el mundo quedaba por el beneficio de las letras (90).

- Divino lo pone Terlingen entre los italianismos "como titulo de honor de personajes excelentesw, pp. 299-30o; pero en el Corlegiano no es solamente titulo, sino cualidad omamental y superlativa, y como tal es de los adjetivos preferidos por Castiglione. "Divinan es la virtud de Isabel Gonzaga (D I, 19-1 3; 12, 9-39; "divinon, el ingenio y juicio de Virgilio ( $\mathrm{I} 30,48-66$ ); «divinen, las estatuas (I 49. 39-95), "divina" puede ser la manera de gobernar (III 35, 35-262); "divina" es por antonomasia la herwosura (IV 59, 5 y 9-380; 70, 3-392). Boscán algunas veces logra escabullirse de tanta ponderación (I I 2, 9-39; 9, 33-36; 3, 37- I I 2; 93, 21-21 7; 4, 17227; 60, I 8-295; IV 36, 42-353; 39, I-356). A veces traduce por rodeos (con un ade Dios" 349. "como a Dios" 354, "más que hombres» 375); pero por la frecuencia con que acepta la palabra puede decirse que forma parte de su vocabulario. 'Tanto es asi que no sólo la conjuga con tan ("espíritus tan divinos" 368), sino que la usa aun sin ser obligado a ello: "diviene austero" (IV 40, 3), ulsácense tan graves y divinos (357). 
d'ogni fatica e molestia umana la modulazione, benche inculta, sia

grandissimo refrigerio (ib., 64),

ésta sea con su cantar, aunque a las vezes acaezca ser grosero, un muy grande y ordinario refrigerio de nuestros trabajos y enfados (93),

y más adclante: «le modulazioni» (II I4, I9) - «los buenos puntos» (I25).

In las fuentes clásicas, que tanto frecuentaba Castiglione, se une a menudo la música con la danza, unión que el Renacimiento gustó de subrayar ${ }^{1}$. Varias veces, en el curso de la obra, Castiglione señalará que el cortesano ha de ser buen bailarin (cf. II II - I2I).

En el vocabulario de la danza, Boscán se deja en el tintero algunos términos específicos ("ballarono una roegarze» [I $56, I]$ - "bailaron con tanta gracia..." [IO3]; "bailando la moresca" [II 6, I3] - "bailando" [II4, cf. ib. 22 - II5 y II 43, 29 - I65]; "bailar moresche e brandi" [II II, II] "bailar sueltamente los bailes que entre hombres de bien se usan" [I2I]. Asimismo atenúa Boscán lo que hay de especlfico en la advertencias del original:

uon entri in quelle prestezze dei piedi e duplicati rebattimenti (II II, 7),

no cure de dar saltillos ni hacer habilidades ni meter mucha obra (121; véase con respecto al canto, I 28, 38-62).

Los únicos dos términos que aparecen en la traducción son los de la baxa y de la alta (I 56, ro - ro3), nombres de dos danzas muy difundidas tanto en España como en Italia:

avendo danzato una bassa $(I 56,9)^{2}$. danzaron una baxa y una alta (103).

Típica del Renacimiento es la elevación de las artes figurativas por encima del lugar que habían ocupado en la teoría medieval y aun en la de los clásicos ${ }^{3}$. Eista tendencia concordaba además con los gustos personales de nuestro autor, que en su juvenil estancia milanesa habia

1 Cf. el Trattato dell'arte del ballo de Guglimimo EnRro Prasarese (ed. Bolonia 1873), pp. 3 y 6-7, citado por P. O. KRISTEL,LER ell "The Modern Syste of the Arts" en Journal of the History of Ideas XII (195I), 5 I 2.

- Sobre estos bailes, véase la nota de CIAN al lugar citado.

- Cf. J. Scrilosser, Die Kunstliteratur/Ein Handbuch zur Quellenkunde der neueren IKunstgeschichte (Viena 1924), pp. 50, 79 y ss., 98, r36, 138, 385. Iste importante trabajo está traducido también al italiano (La letleratura artistica [Florencia 1935]. 
estado expuesto al fervor artístico de la corte de Ludovico el Moro, y que en Urbino coincidió con Rafael, con el cual le unieron lazos de íntima amistad ${ }^{1}$. La correspondencia toda, y la célebre Oratio ad Papam, anónima, pero generalmente atribuida a Castiglione, son fuentes de primer orden para la historia del arte en el Renaciniento (cf. Iirtl. I2-22). Nuestra visión de la figura del humanista italiano será completa sólo si le vemos contra el fondo de su pasión artística y de su entrañable amor por las ruinas arquitectónicas que atestiguan las pasadas grandezas de la Roma antigua ${ }^{2}$. Sin embargo, nos tendremos que ceñir a las observaiones esparcidas en el texto del Cortegiano, y aún alli, a las palabras que dan pie para contrastar el léxico italiano y el español.

Iimpezando por la pintura, vemos que Castiglione se la encomienda insistentemente al hombre de corte ( $I$ 49, 4). Varias veces, en el transcurso de la obra, deja aflorar la similitud entre la composición literaria y el arte de pintar ("sicut pictura poësis»), tópico tradicional sin duda ${ }^{3}$, pero enriquecido por la convicción personal de nuestro humanista. Así, ya en la Dedicatoria, la acostumbrada caplatio benevolentiae se entreteje con la comparación que Castiglione liace de sí mismo con un

pittor ignobile, e clie solamente sappia tirare le linee principali, senza adornar la verità di vaghi colori, o far parer per arte di prospettiva quello che non è (D 1,65 ),

pasaje que Boscán traduce casi a la letra:

un pintor muy baxo y mal diestro y que solamente sabe dibuxar, asentando las lineas principales sin acompañar ni hermosear la verdad con la lindeza de las colores, ni hacer parecer por arte de perspetiva lo que no es (15).

Considérese la versión en su aspecto verbal. El tecnicismo "tirar le linee» no pasa tal cual al castellano; sí se conserva, en cambio, la voz perspetiva,

1 Cf. la tesis de la Universidad de Munchen de I. IirTr, Baldassare Castigliones Beziehıng und Verhälınis zu den bildenden Kü̈nsten (Nurenberg 1933).

2 Véase especialmente la Oratio ad Papam incluida en la edición de G. y G. VorI de las obras de Castiglione (Opere volgari e latine. Padua 1733). Aunque anónimo, este importante documento contiene indiscutibles indicios de ser debido a la pluma de nuestro mantuano (cf. ERTL, op. cil., pp. 23-44).

- Sobre la tradición de este concepto (de que la pintura también es initación de la naturaleza y que por tanto no es inferior en dignidad a la poesia) cf. W. G. HoWARD, "Ut pictura poesis", Publicalions of the Modern Language Association of America 24 (1909), 40-I 23, y R. W. Lisw, "Ut pictura poesis: 'The Humanistic Theory of Painting", The Art Bulletin XXII (1940), pp. 197-269. 
término técnico de los más difundidos en castellano ${ }^{1}$, y que nuestro traductor volverá a emplear más adelante (I 5I, I8 - 97). El verbo disegnare lo traduce con dibuxar o con trazar ( $149,23-95$ ), o con los dos (ib. 4- 94) ${ }^{2}$, mientras que en el sustantivo disegno le lleva a buscar una circunlocución:

I benchd diversa sia la pittura dalla statuaria, pur l'uua e l'altra da un medesimo fonte, che è il bou disegno, nasce (I 49,37).

$Y$ puesto que sea diferente la pintura de la esculptura, la una y la otra uacen de una misma fuente, que es la buena traza o figura que el oficial en si concibe para la obra que ha de hacer (95).

En la versión se desdobla la palabra disegno, y se particulariza en tal manera su contenido que queda eliminado un principio fundamental de la teorla artística del Renacimiento: el ser el diseño elemento común y lazo de unión entre las artes figurativas. Huelga decil que hoy, hablando de esta función unificadora, los historiadores españoles se valen de este término|3. Se cumple así el deseo de Juan Valdés, expresado en el Diálogo de la lengua, de sacar del italiano las voces deseño y deseñar (ed. cit. p. 139), y recobra su pleno sentido un término que los tratadistas ibéricos habían empezado por emplear casi exclusivamente para el dibujo arquitectónicos.

Traducción literal es la de "lo claro y lo oscuro (97), cuyo préstamo ha sido atribuldo a Juan de Mella ${ }^{5}$, y que causará mucha vacilación en

1 También ell el tratado de FrAncisco DE Hol,ANda De la pintura antigua ( 1548 ), traducido al castellano por MANUEL DEN fs (1563), aparece sin glosa esta voz (cf. el capitulo 39, "De la perspectiva", p. I 3 de la edición de Madrid, I921). Asimismo, en el "Vocabulario de nombres obscurosi que se halla como apéndice en $M$. Vitrubio Pollion de architectura..., traduzido de Latin en Castellano por Miguel de Urrea Architecto (Alcalá I582).

- Trazar tiene su sentido particular correspondiente a traza (cf. DrEGo DE SAGREDO, Medidas del romano, une estás esperando con el compás en la mano para començar la traça de las basasn, ed. de F. SANCHEZ CANTón en Fuentes literarias para la historia del arte español, vol. I. Madrid 1923, p. I7), pero a menudo hallamos juntos trazar y dibujar como si se tratara de sinónimos.

- Cf., por ej., M. Gómez-Moreno ell Las águilas del renacimiento espainol. Madrid I94I, p. II.

- No puedo menos de recordar Os deseenhos das antigualhas que vio Francisco d'Ollanda. pintor portugués ...1539-1540...) publicados en magnifica edición facsimil por E. Torno (Madrid I540), que nos demuestran al vivo cómo se eiupezaron a propagar en la Península Ibérica diseños de Italia.

- TerLingen, p. 108, cita al marqués de Santillana como testimonio del empleo de éste termino. Trátase en realidad del título de una composición en la que el poeta cuenta sus citas amorosas ( Otra obra suya llamada Claro escuron). Cf. el Cancionero casiellano del siglo XV (Madrid I9I2), vol. I (XIX dela NBAE), p. 108. 
los teóricos de la pintura ${ }^{1}$. Literal -y cambiadiza- es también la versión de otro térnino consagrado, lume:

i lumi e l'ombre ( ${ }_{51}, 9$ y 18 ) - los lustres y las sombras (97).

i lumi de'rilevi (II 7,34 ) - los resplandores de los relevados (I 6 ).

Iin este capítulo Castiglione se hace eco de un concepto de mimesis que en su origen se remonta a Platón y a Aristóteles, pero que nuestro autor pudo haber aprendido de Plinio (XXXV 34, 4, 9, I2) o de Cicerón (De or. I 32), y que veía repetido por León Bautista Alberti, Filarete y Leonardo (cf. Ertl. 52). Sobre todo estos dos últinios se dedicaron a demostrar cómo la pintura logra imitar a la naturaleza gracias a los colores, a las luces y sombras, y a la perspectiva. Tanto Alberti como Leonardo, además, subrayaron la inportancia capital del relieve; Leonardo, hasta el punto de juzgar por él la capacidad del pintor.

Ahora bien, mientras que Castiglione hereda estos términos con todo el contenido ya consagrado por la tradición, para Boscán no han adquirido aún el carácter de tecnicismos, sino que los traduce como puede, echando mano de las palabras que en cada caso le parecen más apropiadas; $y$, en efecto, aún años después, los tratadistas seguirán revelando la misma vacilación. Véase, pues, cónı se las arregla nuestro intérprete para verter tondo y scorto:

Ii se ben il pittore non fa la figura tonda, fa que'musculi e membri tondeggiati (I $5 \mathrm{I}, \mathrm{x}_{2}$ ).

$\mathrm{Y}$, puesto que en el pintar no se haga la imagen redonda ni maciza, hácense todavia las junturas y los miembros como macizos y redondeados... (97; cf. I, 50, 22-96, tondo- macizo):

in far quelle membra che scortano e diminuiscono a proporzion della vista (ib. I $G$ ).

en hacer aquellos miembros que se han de medir a la proporción de la vista por la perspetiva (ib.)?

Iil esfuerzo que hace Boscán en la transfusión de estos conceptos se cvidencia en el inciso "por una cierta manera que no se sabe decir». Aun palabras que a nosotros nos parecen del todo corrientes, como superficie, le hacen acudir a su acostumbrado recurso de hablar por rodeos:

1 Cf. en la citada obra de HoI,ANDA: "De la luz o lumbre o claro de la pintura* p. 103, "cle la sombra y escuro de la pintura" ,p. ro5; "del blanco y negro", p. 107, idel pricto y blancos (ib).

2 In el tratado De la pintura antigua se le llamará realzo (cf. p. I03, y la definición, "el realzo es otra luz wás clara que la luz natural", p. IO4). IELIPE DE GUE- 
in una tavola, nella qual non si vede altro che la superficie, e que' colori (I 50, 23),

en una inagen pintada, en la cual no se ve sino lo de encima, y las colores (96):

la pittura solamente si veda nella superficie ( 5 I , 7). las pinturas solamente se parezcan en lo de encima (97):

una superficie di muro dritto (I 5 I, 19), un muro pintado derecho $(97)^{1}$.

En cuanto a la escultura, ya vimos en el pasaje citado arriba que Castiglione se refiere a ella con el nombre de statuaria, y con otro término deducido de la más noble materia de este arte, la marmoraria (I 50, I6 y 26; 5I, 3). Estatuaria (y estatuario) se emplearon también en España ${ }^{2}$. Pero Boscán, al traducir, prefiere la voz que luego prevaleció tanto en español como en italiano: esculptura y esculpir (98). Al marmorario (I 5I, II), le llana también esculptor (97).

En cambio, statua le inspira varias traducciones: mármol (I 40, 26 - 62), medalla (I 30, 20-66); sólo con cierta vacilación emplea estatua (I 52, 40 - 99; II 3, I5-II2), cultismo al cual prefiere casi siempre la voz popular bulto (I 2, $27-28 ; 49,36$ y 39 - 95; 50, 6 - 90; 5I, 6 y 9 - 97).

Ahora bien, cualquiera que sea el origen de bullo, en los siglos XV y XVI parece haber tenido ya esa connotación de cuerpo o masa que sugiere hoy a nuestra inaginación ${ }^{3}$, y que le lace tan poco apropiado para ser término de arte, mientras que se acompaña muy bien con esos pedazos de antigüedades que nos llamaron la atención en el capítulo anterior .

VARA en sus Conientarios de la pintura ( 1560 ?) hablará de relievo y relieve (Sánchez Cantón, Fuentes I, I64 y 165).

2 En el siglo XV hallo el calco sobrehaz (cf. La vida y costumbres de los viejos filósofos, traducida de Gunr,erro Buruey y publicada por H. KNUST (Tubinga 1886), p. 157, en la serie de la Bibliothek des litterarischen Vereins in Stuttgart, 177).

2 Sin embargo, también en castellano empezó por utilizarse como sinónimo de escultura. Véase en DIEGO DE SAGREDO, Las medidas del romano I526): asingularisimo artifice en el arte de escultura y estatuarian (SANCHEZ CAN'ÓN, Fuentes I, I4 y 15). Asimismo, CRISTÓ́BAL, DE VILLAL, ON en su Ingeniosa comparación entre lo antiguo y'lo presente (Madrid I898), no habla de escultura y escultor sino de estaltuaria y estatuario (cf. por ej., la p. I52). Más tarde en el tratado de Holanda hallawos un capitulo ede la pintura estatuaria o esculpturan (loc. cit., x21).

- Recuérdese, por ej., el pasaje del Doctrinal de caballeros de Aronso DE CARTAGENA: AAsl como en el espejo se considera el bulto corporal, asl las historias leyendo los fechos agenos, se veen los propios con los ojos del coraçon, (Prólogo).

- Italianismo parece, por la terminación, la voz bronzo (I 2, 27-28; 49; 36-95; IV 9, 19-324); pero Boscán escribe también bronce (I 49, 36-95). 
Esto nos lleva a hablar de los términos de arquitectura, que habrá de traer de varios lugares del Cortegiano. En efecto, ni la escultura ni la arquitectura aparecen entre los (ornamentos» del hombre de corte; la escultura la pone Castiglione por debajo de la pintura, aduciendo para ello los acostumbrados argumentos de la mayor cercanía de la pintura a la naturaleza (I5I). Pero aficionadísimo fué nuestro humanista a ambas y muy curioso cultor en especial de la arquitectura. Essta, además, le brinda ejemplos para ilustrar la f́ntima unión entre lo útil y lo bello (IV $58,3 \mathrm{I}$ ), unión fundamental para lector tan asiduo del De oratore (cf. III 45-46) como lo fué Castiglione. Pero el fin comparativo que perseguimos nos induce a contentarnos, una vez más, con un escueto glosario:

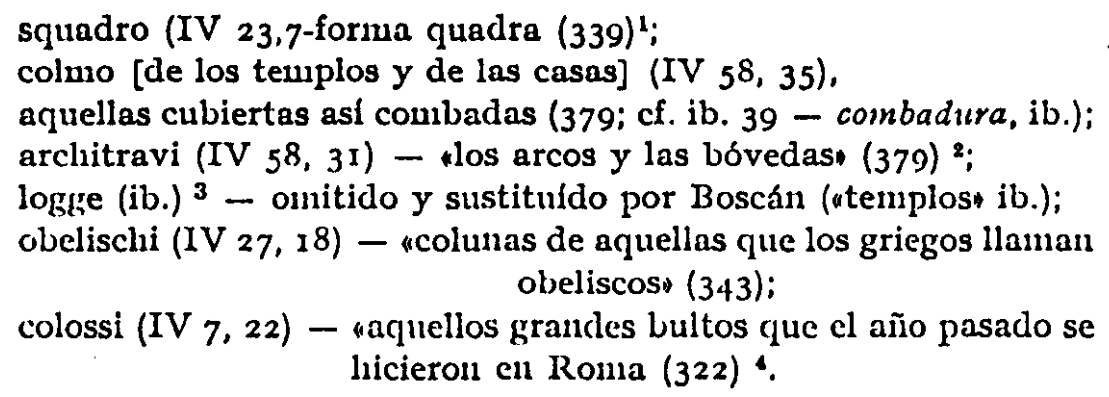

Aun las alusiones sucltas dan testimonio de la atención con que nuestro humanista miraba alrededor suyo, y del aprecio en que tenía a la arquitectura. Pero hay una palabra que quiero destacar especialmente porque evoca el lugar mismo donde se desenvolvió el asunto del Cortegiano, y delimita el ambiente físico en el cual se mueve el hombre de corte ${ }^{5}$. Esa palabra es palazzo.

1 Cf. TERrincen, 138-9, donde se registran sólo las formas esquadrado y quadrado.

2 Véase cómo se explica arquitrave en el Vocabulario de nombres obscuros del traductor castellano de Vitrubio; $₫$ Miembro que passa de columna a columna assentado en los capiteles, junta el edificiow. En el texto de la versión, sin embargo, aparece architraue sin glosa ni explicación (cf. fols. $43 \mathrm{~V}$ y $44 \mathrm{r}$ ). Cf. también SAGREDO, op. cit., p. 18, y IIOr,ANDA, op. cil., p. 127 .

- Cf. 'Iniu,INCre, p. r34, s. v. lonja. Sin embargo, lonja puede considerarse como italianismo sólo en esta acepción arquitectónica. Cf. J. DE VAL,DÉs, Diálogo de la lengua, ed. cit., p. I 31 .

- Coloso será término familiar en la segunda mitarl del siglo. I,o hallo en el tratado de IIolanda, p. 12 I, en la traducción de Virrrunio, ed. cit., fol. $44 \mathrm{r}$, y ell otros escritos.

- El que no haya tenido la suerte de ver Urbino con sus propios ojos lo hallará bellamente ilustrado, por ej., en el excelente libro de Mr. SAI,MI, Piero della Francesca e il Palazzo Ducale di Urbino (Filorencia 1945). 
Conocida es la ambición de los señores de Italia, quienes cifraban su honra y placer en magnfficos palacios. ¿Y España? Aparte el hecho de que aqui la arquitectura profana habia ido a la zaga de la arquitectura religiosa, y que las ciudades españolas llamaban la atención de los visitadores extranjeros por la modestia de sus viviendas, nadie ignora que la vuelta del siglo XV y los principios del xvi vieron un auge considerable de la casa señorial (recuérdense los castillo-palacios de la Calahorra y Vélez Blanco). Es significativo, además, que justo cuando escribla Boscán, una de la águilas del Renacimiento español, Pedro Machuca, empapado de reminiscencias arquitectónicas italianas, estaba construyendo en la Alhambra una residencia adecuada - si no al ambiente - a la dignidad del Enmperador.

En España, el palacio de Carlos V eln Granada consagra, como ningún otro edificio civil, la aceptación de los cánones estéticos italianos ${ }^{1}$. Nos muestra, sin embargo -y por esto lo traigo a colación -, que el lenguaje va a la zaga de los hechos. Carlos $V$ habla pedido que se le construyera una casa ${ }^{2}$ y todos los documentos hablan de ala casa realn ${ }^{3}$. Alcázar lo llamarán los poetas", con un anacronismo que choca nuestro sentido de la

2 Véase la descripción que de él hace, y los arquitectos italianos con cuyas obras le compara GOMrz-Mormino en su mencionado libro, p. 123 y ss.

- Recuérdese lo que escribe Sandovar, "De los ochenta mil ducados que los moriscos dieron, libró diez y ocho mil, para que le comenzasen a hacer una casa en la Allambra...s, Historia del emperador Carlos V XIV, 18 (ed. de Madrid 1847 . vol. II, 453).

3 Por ej., en los documentos recogidos en el apéndice del libro de Gómez-Moreno, pp. 227 y 228, y también los que cita M. GÓmiz-MORENo (padre) en su ensayo histórico sobre el "Palacio de Carlos V en la Alhambra", Revista de España CIII (1885), p. 215: Casa real era la expresión corriente; pero no la única. Villalón, por ejemplo, nos habla del "palacio imperial que hizo Francisco de los Cobos» en Úbeda, loc. cit., p. 173, y anteriormente Diego de Valera menciona al palacio junto a otros edificios: Iglesia mayor o monasteiro o palacio donde aya alguna gran sala èd. Bibliófilos espainoles, XVI, pág. 52. "Palacio, según las Partidas (II 9, 29), es dicho aquel logar do el rey se ayunta paladinamente para fablar con los hoinesn (ed. cit., II 85). En este sentido de residencia del rey y conjunto de sus ministros, la voz palacio se encuentra a menudo en textos de la Edad Media. Tiene, además, sentidos jurldicos y administrativos precisos, tanto en latin como en castellano: ait cum Judas... pactet centum marcas de auro ad palatium regis" (Fuero de Zamora, ed. A. CAstro y $\mathrm{F}$. DE ONís, p. 14). Cf; también Mayer, op. cit. II 219 y el Fuevo Vicjo 5 III 4,6). Quizá esto, y el hecho de que palacio en la Ledad Media significara esala" o chabitación" (cf., por ej., Lba. 48r y passim) harla que en el sentido arquitectónico se hablara mís bien de casa o de casa del rey.

- Véase, por ej., la "Iipistola a Juan Tellez Girón» de Vicentre Espinki, que cita Cienn-Bierni údiz a propósito del palacio de Carlos V. Aun en los tratados de arte, alcázar se destaca, entre las palabras de origen griego y latino que van inva- 
adecuación de palabras y estilos, pero que podría considerarse simbólico de la breve duración en la Península de la línea renacimental pura y la pervivencia del arabesco, que en una u otra forma ornamental vuelve a cubrir las formas arquitectónicas hispanas. Pero aquí queremos subrayar el encuentro, en la realidad, del término antiguo con la nueva creación, y el cruce, en los escritos literarios, de las dos voces. Aún en I559, en la Diana de Montemayor, obra en la cual se ha puesto de relieve "un complaciente gusto en el relato de las características de edificios bellos", conviven los términos casa y palacio ${ }^{1}$.

Antes de concluir estos apuntes sobre "iel mundo del cortesano" habrá que rozar de refilón otro punto importante que asoma en las páginas del libro de Castiglione. Como es sabido, el Renacimiento italiano elevó las artes figurativas a cumbres no conocidas antes, siquiera en la antigüedad clásica, sacó a los artífices de las filas del artesanado y otorgó a su actividad el grado de profesión liberal ${ }^{2}$. Esta ascensión es particularmente notable en el caso de la arquitectura, que la Iidad Media contara entre las artes mecánicas ${ }^{3}$. La introducción del término griego -y latino- en lugar de lus nombres que habían prevalecido en el perfodo medieval (magister opcris, protomagister, magister fabricae, lapicida, cementarios y otros), eleva aun verbalmente a los que conciben y planean los edificios, por encima de los que los construyen y adornan. Con esto no queremos divorciar del todo teoría y práctica, pero es indudable que en la Italia del Qualtrocento la profesión del architetto, representada por inge-

diendo este sector del idioma. Por ej., ell el libro De la pinhura antigua (donde, desde luego, se nos habla también de palacios), se lee la enumeración siguiente: "El anfiteatro y el circo y la curia y el alcázar y la naumaquia y el delubro.... (ed. cit., p. 130).

1 Edición clás. cast. (Madrid 1946), p. 163; F. López Estrada es el que ha destacado más este elemento de la Diana.

2 Cf. el citado tomo de SCHLOSSER y, para una sintesis, el artículo de P. O. KRISTLI.1,ER: (The Modern System of the Arts", Journal of the History of Ideas XII (1951), pp. 510 y ss.

3 Castiglionis recoge todavia este concepto cuando concede (para demostrar lo contrario), que la pintura lloy ell día quizá es tenida por mecánica (I 49, 6-94). Recuérdese que las siete artes mecánicas, según la serie formulada por HUGO DE

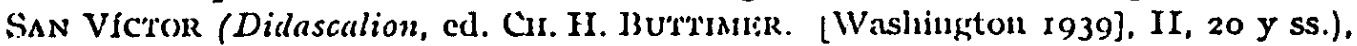
que a su vez influyó en toda la baja lídad Media a través de Santo Tounás y de Vicente de Beauvais, eran las siguientes: lanificium, armatura, navigalio, agricultura, venatio, medicina, theatrica. I a arquilectura y otras ramas del arte figurativo se nombran debajo de la armadura. Cf. KinistieliliR, loc. cit., pp. 507-8, y, para la arguitectura, el exhaustivo ensayo de $N$. PisvSNis "The 'Term 'Architect' in the Middle Agesn, Speculum XVII (1942), 549-56.2. 
nios como un Brunelleschi, un Branante o un Sangallo, viene a ocupar un lugar muy superior al de la masa de constructores $y$ decoradores ${ }^{1}$.

¿Cuál fué la situación de los artifices en España, y en especial, la de de los arquitectos? También aquil se recoge el eco de la controversia. Diego de Sagredo pone la pintura y la escultura junto al 'Trivio y Cuadrivio y hace aliberales" a sus cultores (loc. cit., p. I6). Lo cual no impide que todo su trabajo se dirija a "los officiales del arte", y que dé el mismo título tanto a Cristóbal de Andino (p. I7) y a alos buenos oficiales y los que dessean que sus obras tengan authoridad" (ib.), como a los menesterales más humildes.

Villalón, por otra parte, pone a la arquitectura entre las artes mecánicas ${ }^{2}$. Además, para apreciar la posición de la arquitectura en la mente de los españoles es significativa la sincera sorpresa con que, en las últimas décadas del siglo, los divulgadores de la materia arquitectónica descubren que Vitrubio fué libcral: "no habla como quien obra con las nanos, sino que las cosas de que trata declara con diffiniciones sacadas de las fuentes de las artes liberales y como de tales tomadas) ${ }^{3}$.

En la práctica vemos por las inscripciones y documentos que los cabildos catedralicios y las autoridades ciudadanas tuvieron gran aprecio hacia los maestros a los cuales comisionaban sus obras * I a terminologla medieval (maestro, maestro mayor, maestro de obra, carpintero, a los cuales se añade luego aposentador del rey) sigue usándose durante mucho tiempo ${ }^{6}$, mientras que arclitectus, después de aparecer esporádicamente

1 Cf. el artículo Architetton de G. GIovannont, en la Enciclopedia italiana IV, pp. $5^{8}$ \& ss. y el libro de M. S. RigGs, The Architect in History (Oxford 1927), pp. 130 y ss.

2 VuLLALÓN, en su Ingeniosa comparación (1539), destaca la excelencia de la arquitectura, la pintura, la música y. la estatuaria para defensa del florecimiento de las sartes mechanicas" entre los antiguos (ed. cit., p. 147).

3 Citado de la traducción de Vitrubio, que SANCHEz Cantón atribuye a Iá. zaro de Velasco (1550-1665?) (Fuentes I, 192), y cuyos preliminares son de sumo interés para este tema de la arquitectura ell España.

- Cf. el primer tomo de I. Llaguno y almirola y J. $\Lambda$. Cean-Berriúdiz, Noticias de los arquiteclos y la arquitechura de España (Madrid 1829). Desgraciadamente las inscripciones y documentos no están transcritos con criterios paleográficos y filolúgicos. De este libro han pasado varias inexactitudes a las obras extranjeras de vulgarización.

- Iin 1786 y 1794 respectivamente fueron nombrados don Dicgo Íópez Durango y don Ignacio Ham para el cargo de maestro mayory de la catedral de 'loledo, cf. Ci:AN-Bi:Rnúdizz, op. cil., p. 254. 
en latín ${ }^{1}$, empieza a menudear, al lado de los términos tradicionales, en la segunda mitad del siglo $\mathrm{XVI}^{2}$. Es entonces también cuando se vierten al castellano - con grandísimas dificultades y compromisos idiomáticos - los tratados de arquitectura de Serlio (I552), de Paladio (I578), de Vitrubio (1582), de I,eón Bautista Alberti (1582), de Viñola (1587).

Cuando traducía Boscán dudo que estos conocinientos estuviesen divulgados más allá de la profesión misma ${ }^{3}$. A ésta se dirigía, como vimos, el tratadito de Sagredo ( $\left.{ }_{5} 26\right)$, único, por lo que nos consta, en lengua vulgar. Por él sabemos también que el término arclittetto era palabra desusada en castellano ${ }^{4}$. No nos extraña, pues, que Boscán, antineologista y poco dado a tecnicismos, eche mano a la palabra arraigada en la tradición castiza. Me reficro a oficial, que enplea en el pasaje citado arriba (I 49, 39-95) refiriéndose a la pintura, y para traducir artefici:

gli antichi e l'arte e gli artefici aveano en grandissimo pregio ( 1 49,33),

los antiguos la estiunaban e hacian gran honra a los oficiales della (95).

O/icial le sirve, asimismo, para traducir arclilello (IV 39, 15-356). Y como si esto no bastara, nos demuestra palınariamente que no tiene escrúpulos en llamar a los architetti de Castiglione, con nombre mucho más humilde, "los albañís" (IV 23, $7-339)^{5}$.

1 Por ej., en la capilla del Colegio Mayor de San Ildefonso de Toledo se le llama asl a Gumiel: Petrus Gomelius Complutensis, Academiae architectus) (cf. CranBLiRḾ́nEz, p. I зo).

3 Gustan de llamarse archilectos los traductores de obras de arquitectura en las portadas de sus ediciones (asl Villalpando, Urrea y otros). También se lialla este térnino como título oficial. A Juan de Herrera, por ej., se le llama tan prouto "Maestro de las obras del rey" como arquitecto y aposentador de Palacio" (CranBERMÚdez, p. 333).

- Es PAImireno, en cambio, en el último tercio del siglo, pone los términos de arquitectura entre los temas de conversación (El estudioso corlesano. Valencia 1573, p. 53). Véase cómo se juntan alli los témuinos albañir y arquitectura, y cómo la teoría está subordinada a la práctica auıque no sea más que el saber conversar: Algunas vacaciones vete a ver alguu castillo, torrc, templo o monastcrio que labrau; hazte muy amigo del Albañir, o maestro de architectura, y leyendo a León Baptista, a Sebastián Serlio, a Philandro, a Daniel 13árbaro sobre Vitrubio y medidas del Romano, impresso en Toledo, podrás tratar con él, p. 47.

- Uno de los interlocutores del Dicilogo. Picardo (de profesión pintor) ignora el significado de esta voz: se assimesmo [te ruego me digas] qué cosa es architeto, que tantas vezes por ti es nombrado»; a lo cual el autor, por boca de Tampeso: has de saber, contesta, que architeto es vocablo griego; quiere dezir 'principal fabricador', e assi los ordenadores de celiticios se clizen propiamente architetosn, p. pr 5-I 6.

- Haré notar que ain muclio más tarde (156I) tambićn linomas Honv, ell su versión del Corlegian, alcunis de dar prueba de una tosquedad de léxico aún mayor que la de Boscán. tradıce archiletii con carpenters (cf. la ed. de I,ondres, 1900, 1). 3 I4). 
Asi, las palabras nos revelan las distintas medidas y patrones según los cuales nuestros dos escritores recortan el escenario del mundo cortesano, escenario que se proyecta en la figura del hombre de corte, y que es a su vez iluminado por éstc. No hay lugar, en el ámbito de realia, para examinar las teorías de Castiglione en lo que éstas tienen de estético. Además, su afición por el arte se manifiesta, sobre todo de una manera estillstica, en la expresión verbal, y especialmente en esos medios calificativos que hemos entresacado y entresacaremos en otras ocasiones. Aquí nos ha servido, en parte, de esquema el argumento de las probitates o destrezas, lugar común, casi, por su antigüedad ${ }^{1}$, pero siempre utillsimo para aquilatar los climas culturales de las distintas épocas y países. Gracias a él hemos podido sorprender un momento inicial del Renacimiento español, acogedor de las ideas y de las cosas, pero refractario aún a adoptar sus nombres.

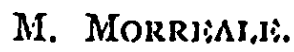

1 Huelga recordar que la lidad Media recopiló en núnero de siete también las habilidades o probilates (vénnse ellumeradas, por ej., en la Disciplina clericalis de Pisdo Alronso: «equitare, natare, sngittare, cestibus certare, aucupare, scaccis ludere, versificaren, [ed. Madrid-Granada 1948], p. 19). Iin la medida en que las probilates se couvierten en forma de vida y de cultura, nos interesan como antecedente de nuestro tema. 